\title{
Gleichschaltung: o princípio do totalitarismo em Ernst Cassirer
}

\author{
Gleichschaltung: the principle of totalitarianism in Ernst Cassirer
}

\begin{abstract}
Rafael Garcia*
Universidade de São Paulo, (USP), São Paulo, SP, Brasil
\end{abstract}

\section{Resumo}

O presente texto tem por objetivo discutir a concepção de totalitarismo na obra de Ernst Cassirer, buscando compreender de que modo ela pode ser entendida essencialmente como a efetivação de uma Gleichschaltung, na acepção que esse termo recebeu no pensamento nazista, ou seja, de uma coordenação no sentido de uma uniformização que tinha por objetivo a eliminação de todas as outras formas de vida social e cultural e suas distinções. Serão três as nossas aproximações com a questão do totalitarismo em Cassirer. Iniciaremos com a consideração do lugar do mito na reflexão política de Cassirer, presente desde seus primeiros artigos sobre política da última fase de sua produção teórica (a partir de 1935), mas que ganha especial destaque em sua última obra preparada em vida, O mito do Estado (1946). A partir disso, procuraremos compreender as técnicas dos mitos políticos modernos, nome do capítulo nevrálgico d'O mito do Estado e conceito mais caro desenvolvido nessa obra, considerando em que medida

* RG: Doutor em Filosofia, e- mail: raroga@hotmail.com 
elas podem ser tomadas como necessárias e ou suficientes para o estabelecimento da Gleichschaltung, termo empregado pelo próprio regime nazista que, segundo o uso feito por Cassirer, sintetiza o modo pelo qual o totalitarismo institui uma atmosfera mítica na sociedade, condição necessária para sua eficácia. Assim, pensamos poder responder à frequente questão no estudo do pensamento político de Cassirer, sobre se sua concepção de totalitarismo foi pensada e pode ser aplicada a outras experiências totalitárias que não a do nazismo, exemplo maior de sua reflexão nos anos do governo de Hitler.

Palavras-chave: Gleichschaltung. Totalitarismo. Mitos políticos modernos. Técnica. Ernst Cassirer.

\section{Abstract}

This paper aims to put into discussion the conception of totalitarianism in the work of Ernst Cassirer, trying to comprehend in which way it can be understood essentially as the accomplishment of a Gleichschaltung, in the sense it was used during the nazi thought, i.e., as a coordination in the sense of a uniformization that aimed to eliminating all other forms of social and cultural life and their distinctions. We will make three different approximations to the totalitarian question in Cassirer. We will start with the place of myth in Cassirer's political works since his earliest papers about politics in the last decade of intellectual production (since 1935), but which achieves special prominence in his last work made during his life, The Myth of the State (1946). Departing of that we intent to comprehend the techniques of the modern political myths, name of the main chapter of The Myth of the State and most important concept of this book, considering in which way they can be taken as necessary and/or sufficient conditions to the establishment of the Gleichschaltung, term used by the nazi regime itself that, according to the use made by Cassirer, synthesizes the way in which the totalitarianism creates a mythical atmosphere in the society, a necessary condition to its efficacy. Doing so we think it is possible to answer the frequent question in the studies of Ernst Cassirer's political thought, if his conception of totalitarianism was thought and can only be applied to the nazi experience or if it allows us to understand other totalitarian experiences.

Keywords: Gleichschaltung. Totalitarianism. Modern political myths. Technique. Ernst Cassirer. 


\section{Sobre a definição de totalitarismo n'0 mito do Estado}

Tal como é bastante comum nos textos de Cassirer, não se encontra n'O mito do Estado, sua principal obra sobre política, nenhuma definição clara do que ele entende por totalitarismo ${ }^{1}$. Com efeito, o termo em questão aparece apenas ocasionalmente em suas obras e em nenhuma delas o filósofo se preocupa em defini-lo². Há contudo, três aproximações que nos permitem compreender a especificidade dessa noção tão cara ao pensamento político do filósofo das formas simbólicas, estes que são apresentados ao longo do texto publicado postumamente, em 1946, bem como nos artigos publicados alguns anos antes e nos manuscritos publicados apenas recentemente, a partir de $1995^{3}$.

Apresentaremos aqui essas três aproximações, que são: (1) a menção ao totalitarismo como um tipo de regime de governo em que a forma mítica suplanta as demais formas simbólicas e as faculdades críticas; (2) a efetivação do totalitarismo por procedimentos técnicos, designados pelo filósofo pela paráfrase técnica dos mitos políticos modernos e; (3) o totalitarismo como o que visa e ao mesmo tempo procede a partir da supressão da diversidade característica da cultura ou da própria Gleichschaltung. A partir desse percurso, pretendemos então delimitar com maior clareza o lugar específico de cada uma das técnicas

1 Exemplo maior de como o filósofo não é afeito a trazer definições claras dos conceitos de que se utiliza é justamente aquele que é o maior e mais conhecido conceito em sua obra, qual seja, o de forma simbólica. Sobre isso tratamos anteriormente em GARCIA, 2014, p. 47-55.

2 Em que se pese 0 grande interesse recente no pensamento político de Cassirer, e mesmo considerando a amplitude e variabilidade das teses e livros publicados, não temos notícia de nenhum artigo ou texto que tenha buscado aclarar a definição de totalitarismo na obra do autor da Filosofia das formas simbólicas. Dentre as obras mais expressivas na análise do pensamento político de Cassirer estão o livro de Tobias Bevc, Kulturgenese als Dialetik Von Mythos und Vernunft: Ernst Cassirer und die Kritische Theorie, que busca aproximar o pensamento político de Cassirer do projeto da Escola de Frankfurt, a tese de doutorado de Pellegrino Favuzzi, Kultur und Staat, que analisa sobretudo os textos políticos de Cassirer antes da concepção do projeto da Filosofia das formas simbólicas, e os livros de Dirk Lüddecke, Staat - Mythos - Politik: Überlegungen zum politischen Denken bei Ernst Cassirer, e de Roman Parkhomenko, Ernst Cassirers Politische Philosophie Zwischen allgemeiner kulturtheorie und Totalitarismus-Debatte. Outras contribuições mais pontuais e recorrentemente citadas ficam a cargo de Fabien Cappeillères e Christian Möckel. Peter Gordon e Andreas Jürgens são ainda dois autores cujas obras tocam em pontos importantíssimos das discussões e situações políticas vividas e pensadas por Cassirer.

3 Trata-se da edição das obras completas, com 26 volumes, e da edição de manuscritos e textos póstumos (com alguns volumes ainda em processo de finalização), com 18 volumes. 
elencadas no segundo ponto de aproximação, o que defendemos, permite-nos dizer com segurança em que medida e em que sentido as reflexões políticas de Cassirer podem ser aplicadas para a compreensão de regimes totalitários em geral, não apenas, contrariamente, ao caso particular do nazismo, mote maior de seus textos. ${ }^{4}$

\section{0 totalitarismo como a sobreposição do mito à razão}

Logo nos parágrafos de abertura d'O mito do Estado, Cassirer, discorrendo sobre a situação social e política então presente, afirma existir uma "mudança radical" no interior das formas políticas até então conhecidas e uma "subversão" da vida intelectual e social causada pela "aparição de um novo poder: o poder do pensamento mítico". Este novo elemento na cena política teria, "em alguns dos nossos modernos sistemas políticos" clara preponderância sobre o pensamento racional, este que sofrera uma "derrota completa e irrevogável" na "vida prática e social do homem" que o faz regressar "aos períodos mais rudimentares da cultura humana"5.

Com estas palavras Cassirer, que não menciona nominalmente o totalitarismo, deixa claro de saída o modo como percebe e tentará lidar teoricamente com o fato do totalitarismo: ele o compreenderá a partir de elementos previamente desenvolvidos em sua Filosofia das formas simbólicas. Destaca-se aqui a presença central da forma mítica de pensamento,

4 Essa é uma questão presente em alguns dos textos de comentários sobre a política em Cassirer. A título de exemplo, citamos aqui Jöel Gaubert, em seu La Science Politique d'Ernst Cassirer, cuja questão geral é justamente avaliar se a incursão de Cassirer no campo da política fora não mais do que um exercício intelectual de um proeminente pensador ou se essa aproximação pode ser compreendida como um desdobramento de seu sistema das formas simbólicas (cap. I). Vale dizer que este texto tem sua inspiração e pretende ser uma resposta às indagações feitas por Christian Möckel, meu orientador no período de bolsa na Universidade Humboldt e membro de minha banca de defesa, em sua arguição à minha tese. Algumas das colocações de Möckel, como a da aplicabilidade do pensamento político de Cassirer para a compreensão dos fenômenos totalitários em geral, estão entre as questões que aqui pretendemos responder. De todo modo, este texto, que a ele dedico, é minha forma de agradecimento ao prof. Möckel pelas inquietações que surgiram de sua dedicada leitura e orientação durante minhas pesquisas.

5 The myth of the State (doravante referido pela sigla MS), p. 7. 
a qual o filósofo dedica o segundo tomo de sua grande obra e que é um ponto-chave para a compreensão de sua crítica da cultura.

Destarte sua visada ao problema que enfrenta como o de um conflito no interior das formas constituintes da cultura - uma breve luta entre o mito e a razão em que o primeiro se saiu vitorioso. Esta breve luta de que fala o filósofo é na verdade o próprio equilíbrio dinâmico e tênue das formas simbólicas em sua interação recíproca, posto que é uma característica das formas simbólicas buscarem por hegemonia ${ }^{6}$. Trata-se de fato de uma harmonia de contrários pela qual o filósofo designa a própria cultura ${ }^{7}$.

Por esta primeira aproximação temos então, que o totalitarismo, visto sob o prisma de uma crítica da cultura e em seus contornos mais elementares, é um desequilíbrio peculiar das forças constituintes da cultura que possui efeitos na vida social e política, no qual algo muito semelhante à forma mítica de pensamento assume a hegemonia da cultura.

\section{0 totalitarismo e as técnicas dos mitos políticos modernos}

No intuito de aprofundar essa primeira aproximação conceitual com o totalitarismo, não tanto com vistas a defini-lo, mas sim esclarecer o modo específico pelo qual foi reavivada a consciência mítica no seio de uma sociedade complexa e bem desenvolvida enquanto tal. Assim, Cassirer argumenta que o totalitarismo se efetivou por um uso consciente e tecnicamente implementado da dimensão mítica da cultura. É assim que surge para o filósofo uma das noções mais caras em sua análise do fato e das condições de possibilidade do totalitarismo,

60 surgimento de novas formas simbólicas a partir da forma mítica não é pacífico, mas sim "um choque entre poderes espirituais conflitantes" (Essay on Man, doravante EM p. 13). "0 avanço consiste em que certas linhas gerais, certas determinidades espirituais dos estágios anteriores não são somente aperfeiçoadas e completadas, mas sim são negadas, são simplesmente aniquiladas." (PSF II, p. 275)

7 Essa menção a uma harmonia de contrários remete a Heráclito. Ao final do Ensaio sobre o homem encontramos Cassirer se referindo à cultura como o produto de tensões permanentes entre formas simbólicas. Mas se trata de uma tensão que, vista da perspectiva de sua totalidade, não apresenta contradição e desarmonia. "A dissonância está em harmonia consigo mesma; os contrários não são mutuamente excludentes, mas interdependentes: 'a harmonia na contrariedade, como no caso do arco e da lira'"' (EM, p. 244).

Rev. Filos., Aurora, Curitiba, v. 28, n. 43, p. 295-312, jan./abr. 2016 
qual seja o da técnica dos mitos políticos modernos. Vale-nos analisar detidamente esta noção.

Ao falar em técnica, Cassirer se remete a uma discussão forte em seu tempo sobre os impactos disto que para ele é uma das formas simbólicas mais elementares da cultura. Em 1930 o filósofo publicou um texto de nome Forma e técnica ${ }^{8}$ no qual busca justamente incluir a técnica no seu sistema de formas simbólicas. Isso, entre outros, significa que Cassirer não se coloca nas fileiras daqueles que veem na técnica e em seu desenvolvimento a causa dos males sociais que acometem a cultura europeia no início do século XX. Integrar a técnica ao sistema de formas constituintes da cultura significa compreender seu papel para o processo de progressiva autolibertação do homem, mas com a ressalva de que a técnica deve ser submetida a um crivo ético - pelo qual as demais formas simbólicas também devem passar. Portanto, é preciso ter claro de que a crítica de Cassirer à técnica n’O mito do Estado não tem o mesmo teor que as demais críticas sobre a instrumentalização da razão, nem, por outro lado, compactua com a visada das filosofias da vida que, segundo o filósofo das formas simbólicas, condenariam a técnica per se. O limite da crítica de Cassirer à técnica é também o mesmo limite que descrevemos acima, qual seja, o de que esta, em sua tendência "natural" à hegemonia, sobrepujou as demais formas simbólicas e causou desequilíbrios na dinâmica da cultura.

Neste sentido é que foram produzidos mitos políticos modernos: tecnicamente. Contudo, estes mitos políticos modernos são em si mesmos uma novidade no cenário e no pensamento político moderno; não se trata aqui de mitos como aqueles que foram historicamente gerados e transmitidos por sociedades antigas e primitivas. Um mito político moderno é diferente, em suas qualidades e características, gerais se comparado a um mito natural ${ }^{9}$. A diferença básica dos mitos

8 Form und Technik, publicado pela primeira vez em Kunst und Technik, Leo Kestenberg (Ed.), Berlim 1930, p. 15-61.

9 A expressão "mito natural" é utilizada por Cassirer no segundo tomo da Filosofia das formas simbólicas para marcar a distinção entre estes, mais primários, e aqueles criados quando já há al gum desenvolvimento cultural, aos quais, justamente, o filósofo dá o nome de "mitos culturais". Diz ele: "Se se tentar compreender esse processo espiritual [de especialização das ações por meio de configurações míticas autônomas] a partir de seu conteúdo, ele se apresenta com clareza na evolução que a consciência mítica leva a cabo, na medida em que ela passa dos meros mitos naturais para os mitos culturais" (PSF II, p. 240). 
políticos para os mitos naturais e culturais reside em seu processo de criação. "O mito sempre foi descrito como o resultado de uma atividade inconsciente e como um produto da livre imaginação", diz o filósofo, "[m]as aqui encontramos o mito feito de acordo com um plano. Os novos mitos políticos não crescem livremente; eles não são frutos selvagens de uma imaginação exuberante. Eles são coisas artificiais fabricadas por artesãos muito hábeis e astutos." 10

Assim, vem à tona o paradoxo essencial do mito político: "em certo sentido, ele é completamente racionalizado. Ele é irracional em seu conteúdo, mas é muito claro e consciente em seus objetivos"11. Os artífices desses mitos políticos também diferiam fortemente do homo divinans das sociedades míticas; eles não estariam simplesmente submetidos ao encanto do mito, mas sim eram técnicos absolutamente conscientes de suas criações.

“Claro que nossos políticos modernos não deixaram de modo algum de ser espécimes bem característicos e perfeitos de homo faber. Eles fizeram uso bastante hábil e metódico de todos os meios refinados e sofisticados que a ciência natural e a técnica colocaram à sua disposição. A esse respeito eles pensavam e agiam como 'racionalistas' estritos."12

A criação dos mitos políticos deve-se então, segundo Cassirer, a uma descoberta puramente técnica, a de que é mais fácil governar os homens pela imaginação do que pela razão.

“Eles [os artífices dos mitos políticos] sabiam por experiência própria que as grandes massas podem ser movidas muito mais facilmente e muito mais rapidamente pela força da imaginação do que por mera força física. Em virtude desse princípio os políticos modernos, o homem do século $X X$, repentinamente se tornou o homo divinans dos tempos anteriores. O líder político se tornou o vates publicus, o adivinho oficial, o seguidor do feiticeiro, o áugure, o astrólogo. A profecia era uma parte

\footnotetext{
${ }^{10}$ MS, p. 277

${ }^{11}$ Myth of the State. The Myth of the State. Its Origin and its Meaning. Third Part: The Myth of the Twentieth Century [doravante referido como MS - Origin and Meaning], p. 200.

12 MS-Origin and Meaning, p. 214.
} 
essencial na nova técnica da política. Foi muito mais pelo uso hábil e inescrupuloso da profecia do que por mera força física que a Alemanha finalmente converteu-se aos novos ideais políticos."13

Em outras palavras, a decisão de governar pelo uso da força não da força física, mas da força da imaginação - é a decisão de romper com qualquer ideal ou expectativa de esclarecimento da população: trata-se de confiná-la à menoridade do juízo cativo das emoções em lugar de elevá-la à capacidade de julgar racional e eticamente o que se deve fazer na política.

Então para fazê-lo, foi necessário adotar algumas técnicas específicas que competiam para estabelecer essa atmosfera mítica. Esquematicamente, Cassirer elenca quatro técnicas. A primeira delas é o mito da raça, que Cassirer aborda a partir do impacto dos textos de Arthur de Gobineau, Essai sur l'inégalité des races humaines, sobretudo. Sobre o mito da raça, Cassirer diz: "foi a teoria totalitária da raça que apontou o caminho para as concepções ulteriores de Estado totalitário"14. Isso porque Gobineau atua para se contrapor diretamente aos ideais humanistas e cosmopolitas do século XVIII em favor de uma história (falaciosa) em que raças distintas tinham por natureza valores distintos. No caso nazista, a noção reificada de raça era ainda turvada pela indistinção entre raça e povo, nação. Lutar em prol da raça ariana e do povo alemão era o mesmo; combater os estrangeiros (Fremde) significava a um só tempo outras nações e outros povos.

Ao mito da raça se somava o mito do destino, que Cassirer pontuou a partir de Oswald Spengler e Martin Heidegger. A técnica aqui aplicada visava fazer a noção de história regressar à noção mítica e determinista de destino, um destino a ser cumprido pelo povo alemão. De outro lado, o destino estava também ligado ao inevitável declínio da civilização ocidental, "profetizado" por Spengler e para o qual a noção heideggeriana de Geworfenheit só vinha a contribuir. Tudo se passa, então, como se a história se reconvertesse numa grande e inexorável tragédia, sobre a qual o indivíduo não teria poder algum.

13 MS - Origin and Meaning, p. 214.

14 MS, p. 228. 
Não podemos impedir o destino, nós não podemos refrear a roda do Íxion a qual estamos atados, ou dar-lhe uma outra direção. Frente aos enormes cursos da vida naufraga toda a existência [Dasein] e todo querer do particular; o indivíduo não pode fazer outra coisa que se entregar a ele e se reconhecer em sua insignificância frente a eles". ${ }^{15}$

O efeito disso é a redução da capacidade de antecipação e previsão de eventos à medida que cresce a necessidade de um adivinho capaz de ler os augúrios do porvir. Efeito extremo do fatalismo do destino é a impossibilidade do agir moral, já que é negada ao homem a possibilidade de liberdade: "[u]ma filosofia da história que consiste em predições sombrias do declínio e da inevitável destruição de nossa civilização e uma teoria que vê na Geworfenheit do homem uma de suas principais características desistiu de todas as esperanças de uma participação ativa na construção e reconstrução da vida cultural do homem."16

A terceira técnica é a manipulação da linguagem. Esta consiste em alterar a função geral da linguagem, fazendo-a regredir essencialmente ao nível da função expressiva, e por este meio, potencializar sua dimensão emocional, de modo que elas passem a evocar "imediatamente" essas emoções - "ódio, raiva, fúria, altivez, desprezo, arrogância, desdém". 17 "A palavra mágica ganha precedência sobre a palavra semântica." ${ }^{18}$ Palavras específicas da língua alemã também tiveram seu sentido alterado para cumprir este fim.

“Essa mudança de significado depende do fato de que essas palavras que anteriormente eram usadas num sentido descritivo, lógico, ou semântico são agora usadas como palavras mágicas que são destinadas a produzir certos efeitos e incitar certas emoções. Nossas palavras ordinárias são carregadas com significados; mas essas novas palavras confusas são carregadas com sentimentos e paixões violentas." ${ }^{19}$

\footnotetext{
15 Naturalistische und humanistische Begründung der Kulturphilosophie, p 151.

16 MS, p. 288.

17 MS, p. 279.

18 MS, p. 278.

19 MS, p. 278.
} 
Se admitirmos a importância da linguagem na filosofia de Cassirer e considerarmos o sentido das três funções da consciência que ele apresenta ao longo da Filosofia das formas simbólicas, depreendemos que a manipulação da linguagem significa fazer retroagir a capacidade de pensar aos seus níveis mais primários, o que também significa tolher a capacidade de reflexão e de crítica ${ }^{20}$.

A última das técnicas dos mitos políticos modernos elencada por Cassirer é a ritualização da vida cotidiana. Trata-se aqui de implantar um processo maciço de ritualização das atividades mais corriqueiras da vida. Há uma dupla função nesse processo. De um lado, ele contribui enormemente para a supressão do pensamento crítico.

“Não há nada que tenha mais influência hipnótica sobre a mente humana do que a execução incessante e regular dos mesmos atos que se seguem um ao outro numa ordem uniforme e mecânica. Por tal atitude passiva todas as forças intelectuais ativas dos homens são embaladas em sono, todo pensamento e julgamento crítico é eliminado. A propaganda por ações é sempre muito mais efetiva e opressiva do que a propaganda por palavras." 21

De outro lado, a ritualização transforma o dever em mera performance de determinadas obrigações rituais. Há um processo de elisão e externalização da noção de responsabilidade pela dissolução da vida privada na vida pública. Por esta via a comunidade popular (Volksgemeinschaft) é colocada em evidência, em detrimento da individualidade, que é pari passu delida. Regressa-se assim a um aspecto fundamental das sociedades primitivas, qual seja, o de que não é o indivíduo o sujeito moral, mas sim o grupo. ${ }^{22}$ Trata-se aqui, em síntese,

200 primeiro volume da Filosofia das formas simbólicas é dedicado à linguagem. Vale ainda mencionar 0 artigo The Influence of Language upon the Development of Scientific Thought, de 1942, em que o filósofo defende a interdependência entre 0 desenvolvimento da linguagem e 0 da ciência, na medida em que a esta precisa criar para si uma linguagem adequada por meio da qual possa lidar com os fenômenos. Quando, diversamente, insiste-se na imediaticidade (mágica) da palavra, perde-se de vista sua capacidade de descrever eventos puramente objetivos.

21 MS - Origin and Meaning, p. 208-9, nota do editor.

22 MS, p. 280. 
de um grupo que se identifica por ritos, pela raça, pelo destino e pela precisão imediata da linguagem.

\section{0 totalitarismo e a Gleichschaltung}

Chega-se assim, ao terceiro momento de nossa aproximação com a noção de totalitarismo. O que as técnicas acima destacadas possibilitam é justamente a efetivação da Gleichschaltung. Diz o filósofo sobre isso:

“Um dos principais objetivos e uma das condições fundamentais do Estado totalitário é o princípio da Gleichschaltung [tornar-o-mesmo; uniformizar]. Para subsistir ele tem de eliminar todas as outras formas de vida social e cultural e obliterar todas as distinções" ${ }^{\prime 23}$

Nota-se que o filósofo não resume ou tampouco define o totalitarismo como Gleichschaltung - coordenação, sincronização, conformação, que assume a acepção de coordenação forçada ou uniformização. Mas toma esse procedimento como indispensável para o sucesso do plano totalitário nazista. O processo de uniformização é justamente o apagar das distinções e das identidades formadas no e pelo processo de desenvolvimento cultural.

Obliquamente a Gleichschaltung nos remente ao cerne da crítica da cultura de Cassirer, na medida em que a uniformização implica delir a diversidade que é engendrada pelo processo conflitivo de desenvolvimento cultural - lembremo-nos de que o surgimento das formas simbólicas não é um brotamento pacífico, mas sim um embate de forças mutuamente irredutíveis do espírito: “os estágios singulares de seu desenvolvimento não se conectam um ao outro simplesmente, mas sim antes frequentemente se enfrentam em nítida oposição." ${ }^{24}$ Isso porque a noção de cultura com a qual o filósofo lida carrega em si uma

23 MS, p. 272.

24 PSF II, p. 275. 
antinomia perpétua, representada, como dissemos acima, na harmonia heraclitiana de opostos.

Nesse sentido, exatamente, a Gleichschaltung aparece como o elemento central da reflexão sobre a perversão que o totalitarismo impõe à cultura. Ora, ela é como que a eliminação de todo o antagonismo, de todo o conflito no interior da cultura e de seus momentos constituintes. Não seria demais dizer que ela é o princípio mais geral do totalitarismo, ao mesmo tempo sua causa e seu telos.

A ligação (indireta) entre este princípio de uniformização e o pensamento mítico é bastante clara quando mantemos em mente que no corpus da obra de Cassirer o pensamento mítico é apresentado como aquele em que nenhuma distinção clara - sequer a divisão entre sujeito e objeto, interno e externo - foi ainda feita. Nesse sentido, e como Cassirer rechaça a ideia de que seja possível simplesmente retroagir, como se num movimento atávico, a Gleichschaltung é a própria atmosfera mítica "artificial" reavivada num contexto complexo e bem desenvolvido de sociedade.

A visada da filosofia da cultura para o fenômeno do totalitarismo seria, por seu turno, justamente atenta ao modo como este atua em sua dinâmica e é capaz de anestesiar seu impulso fundante, que está na espontaneidade do espírito.

\section{0 estatuto das técnicas dos mitos políticos modernos}

Se partirmos das aproximações com a noção de totalitarismo que acima apresentamos, podemos entender as técnicas dos mitos políticos modernos como meios de efetivação da Gleichschaltung. Se isso, de início, é bastante óbvio, talvez menos claro seja que isso reduz cada uma das técnicas apresentadas, segundo enfatizamos o conteúdo específico de cada qual, a um estatuto de mera condição histórica contingente. Em outras palavras, em que se pesem as técnicas específicas que Cassirer apresenta n'O mito do Estado, elas são uma análise que tem aderência tão somente ao caso específico da experiência totalitária 
alemã, de modo que seria vão buscar em outras das experiências que marcaram a vida social europeia a presença dos mesmos elementos.

Vale-nos aqui, lembrar de que Cassirer define as técnicas dos mitos políticos modernos exatamente como uma espécie de catalisador dos elementos míticos dispersos pela sociedade, sobretudo no ambiente acadêmico, que são então transportadas para o ambiente social amplo.

“Para esse propósito [de tirar as ideias basilares dos mitos políticos do âmbito acadêmico e trazê-las ao público em geral] era requerido um novo instrumento - não apenas um instrumento de pensamento, mas também de ação. Uma nova técnica tinha de ser desenvolvida. Esse foi o último e decisivo fator. Para dizer isso em terminologia científica, devemos dizer que essa técnica teve um efeito catalítico. Ela acelerou as reações e deu-as seu pleno efeito. Embora o solo para o mito do século XX havia sido preparado muito antes, ele não poderia ter dado seus frutos sem o uso hábil de uma nova ferramenta técnica." (MS, p. 273)

O uso do termo técnica no singular é um índice do que queremos aqui dizer: a técnica à qual o filósofo se refere é a Gleichschaltung; a uniformização, o apagamento gradual e contínuo das diferenças, da individualidade, da responsabilidade, a padronização dos comportamentos e a supressão do solo necessário ao desenvolvimento do pensamento crítico: tudo isso precisa ser entendido como a categoria mais geral dessa técnica dos mitos políticos modernos, ou a técnica de coordenação totalitária.

As outras técnicas que o filósofo descreve ao longo do texto são vias procedimentais particulares e específicas com determinados conteúdos historicamente engendrados e gestados (como o mito da raça ariana e a mistura entre judeus e marxistas que constituiu o bode expiatório mais amplo), de um postulado mais geral, de um princípio. Assim, elas devem ser compreendidas como os elementos disponíveis que puderam ser cooptados pelo núcleo edificador do ideário nazista.

De outro lado, contudo, quando abstraímos dos conteúdos dessas técnicas e nos debruçamos sobre sua função geral, percebemos, por 
exemplo, que há uma retroalimentação entre a técnica que manipula a linguagem e a técnica de ritualização. Ambas tolhem e delem a liberdade do espírito em sua dimensão teórica e prática. E do encurtamento de uma se segue o encurtamento da outra: os ritos constantes hipnotizam e entorpecem a mente, a mente hipnotizada atua para a simples reprodução do rito.

Da mesma forma, o mito do herói (que Cassirer toma da Thomas Carlyle) tem a função de promover a unidade e solidariedade da Volksgemeinschaft. Ele atua próximo da técnica que transforma a história em destino, na medida em que o herói é a personificação da vontade coletiva. O foco, todavia, está no estabelecimento da unidade do povo pelo apagamento de suas distinções internas e para a consecução de um objetivo comum.

Podemos ainda pensar na questão racial da mesma forma: ela tem a função de estabelecer os limites daquilo que será passível dessa solidariedade, bem como, por contraste, daquilo que será alvo de ataques (os bodes expiatórios) para que o objetivo maior da raça seja alcançado.

\section{Considerações finais}

Destarte, se quisermos procurar nas quatro técnicas dos mitos políticos modernos apresentadas n'O mito do Estado alguma unidade sistemática, esta fica a cargo do princípio da Gleichschaltung: para uniformizar é necessário entorpecer a mente e o corpo, dissolver a vontade individual na personificação de uma vontade coletiva e contrastar essa unidade com aquela outra à qual ela se contrapõe.

Se então, for feita a pergunta sobre em que medida o que Cassirer expõe n'O mito do Estado pode ser aplicado a outras experiências totalitárias, o que se pode responder é que a aplicação é sim, possível, desde que se tenha em conta que o fundamental e inextricável na consecução dos intentos totalitários é o princípio da Gleichschaltung. Pode-se inclusive, aventar que mesmo tendo seu texto uma aderência inegável ao caso da experiência totalitária alemã, o fim de sua reflexão estaria na 
busca por esse princípio fundamental dos sistemas totalitários. Tratase, entretanto, de uma questão que permanecerá ao menos temerária, haja vista a circunstância de edição e publicação de seus manuscritos póstumos d'O mito do Estado. ${ }^{25}$

Aceito este nosso argumento aqui apresentado, todo ou em partes, devemos então, partir para a comparação das diversas concepções de totalitarismo propostas mais ou menos à mesma época em busca de uma compreensão ainda mais profunda no que tange à identificação de seu funcionamento, bem como do que fazer para evitar sua repetição, seja em regimes de facto totalitários, seja naqueles em que ocorre algum grau de manipulação por expedientes tipicamente míticos.

\section{Referências}

CASSIRER, E. Ernst Cassirers Gesammelte Werke [ECW], 26 vol. Hamburg: Felix Meiner, 1998.

CASSIRER, E. Ernst Cassirers Nachgelassene Manuskripte und Texte [ECN]. Hamburg: Felix Meiner, 1995-2015.

CASSIRER, E. Essay on Man: An Introduction to a Philosophy of Human Culture. ECW 23.

CASSIRER, E. Form und Technik. ECW 17, p. 139-83.

CASSIRER, E. Naturalistische und humanistische Begründung der Kulturphilosophie. ECW 22, p. 140-66.

CASSIRER, E. Philosophie der symbolischen Formen I: Die Sprache. ECW 11.

CASSIRER, E. Philosophie der symbolischen Formen II: Das mythsche Denken. ECW 12.

CASSIRER, E. Philosophy and Politics. In: VERENE, D. (Ed.) Symbol, Myth and Culture: Essays and Lectures of Ernst Cassirer 1935-1945. p. 219-32.

25 A esse respeito, ver JÜRGENS, A., cap. V e VI. 
CASSIRER, E. Symbol, Myth and Culture: Essays and Lectures of Ernst Cassirer 1935-1945. Donald Philip Verene (Ed.). New Haven: Yale University Press, 1979.

CASSIRER, E. The Concept of Philosophy as a Philosophical Problem. In: VERENE, D. (Ed.) Symbol, Myth and Culture: Essays and Lectures of Ernst Cassirer 1935-1945. p. 49-63.

CASSIRER, E. The Influence of Language upon the Development of Scientific Thought. ECW 24, p. 115-34.

CASSIRER, E. The Technique of our Modern Political Myths. In: VERENE, D. (Ed.) Symbol, Myth and Culture: Essays and Lectures of Ernst Cassirer 19351945. New Haven: Yale University Press, 1979. p. 242-67.

CASSIRER, E. The Myth of the State. Its Origin and its Meaning. Third Part: The Myth of the Twentieth Century. ECN 9, 2008, p. 167-224.

CASSIRER, E. The Myth of the State. ECW 25.

BEVC, T. Kulturgenese als Dialetik Von Mythos und Vernunft: Ernst Cassirer und die Kritische Theorie. Königshausen \& Neumann, Würzburg 2005.

CAPEILLÈRES, F. Cassirer Penseur Politique: "The Myth of the State" contre "Der Mythus des 20. Jahrhunderts", Cahiers de Philosophie politique et juridique, 24 ,1994, p. 175-204.

FAVUZZI, P. Kultur und Staat: Quellen und Kontext des politischen Denkens Ernst Cassirers. Tese de Doutorado. Humboldt-Universität zu Berlin, 2013. Disponível em: http://edoc.hu-berlin.de/dissertationen/favuzzi-pellegrino-2013-04-04/PDF/ favuzzi. pdf (último acesso em 19/05/2015).

GARCIA, R. Genealogia da Crítica da Cultura: sobre a filosofia das formas simbólicas de Ernst Cassirer. Saarbrücken: Novas Edições Acadêmicas, 2014.

GAUBERT, J. La Science Politique d'Ernst Cassirer: pour une refondation symbolique de La raison pratique contre le mythe politique contemporain, Éditions Kimé, Paris 1996.

GORDON, P. Continental divide: Heidegger, Cassirer, Davos. Massachusetts: Harvard University Press, 2010. 
JÜRGENS, A. Humanismus und Kulturkritik: Ernst Cassirers Werk im amerikanischen Exil. München: Wilhelm Fink, 2012.

LÜDDECKE, D. Staat - Mythos - Politik: Überlegungen zum politischen Denken bei Ernst Cassirer. Spektrum Politikwissenschaft, Bd. 22. Würzburg: Ergon Verlag, 2003.

MÖCKEL, C. Das „Lebensgefühl“ in der politischen Philosophie Ernst Cassirers. Am Beispiel des „Gemeinschaftsgefühls“. In: Jan-Christoph Heilinger / Colin G. King / Héctor Wittwer (Hrsg.): Individuum und Selbstbestimmung. Volker Gerhardt zum 65. Geburtstag. Berlin 2009, 167-182;

MÖCKEL, C. Ernst Cassirers Philosophieder Politik: Rationalität,Unveräußerlichkeit natürlicher Rechte, ethisches Primat. In: Mirko Wischke (Org.): 1. Jahresband des Deutschsprachigen Forschungszentrums für Philosophie Olomouc (PalackyUniversität) 2005, 50-73;

MÖCKEL, C. Hegel-Bilder im Wandel? Zu Ernst Cassirers Verständnis der politischen Philosophie Hegels. In: LOMONACO. F. (Org), Simbolo e cultura. Ottant'anni dopo la Filosofia delle forme simboliche. Milano: Franco Angeli, 2012, p. 187-208.

PARKHOMENKO, R. Ernst Cassirers Politische Philosophie Zwischen allgemeiner kulturtheorie und Totalitarismus-Debatte. Karlsruhe: Universitätsverlag Karlsruhe, 2007.

Recebido: 16/08/2015

Received: 08/16/2015

Aprocado: 20/12/2015

Approved: $12 / 20 / 2015$ 
